\title{
Differential diagnosis between epileptic seizures and psychogenic nonepileptic seizures based on semiology
}

\author{
Xiaohui Xiang ${ }^{1}$, Jiajia Fang ${ }^{1}$ and Yi Guo ${ }^{2^{*}}$ D
}

\begin{abstract}
Psychogenic nonepileptic seizures present as paroxysmal symptoms and signs mimicking epileptic seizures. The gold standard test is the synchronous recording by video, electrocardiogram and electroencephalogram. However, video electroencephalogram is not available at many centers and not entirely independent of semiology. Recent studies have focused on semiological characteristics distinguishing these two circumstances. Clinical signs and symptoms provide important clues when making differential diagnosis. The purpose of this review is to help physicians differentiating psychogenic nonepileptic seizures better from epileptic seizures based on semiology, and improve care for those patients.
\end{abstract}

Keywords: Psychogenic nonepileptic seizures, Epileptic seizures, Semiology

\section{Background}

Seizures can be divided into three major categories: epileptic seizures (ES), psychogenic nonepileptic seizures (PNES), or physiologic nonepileptic events. The majority of patients with recurrent seizures are initially presumed to have epilepsy and are treated with antiepileptic drugs. PNES present as paroxysmal time-limited, alterations in motor, sensory, autonomic, and/or cognitive signs and symptoms, but are not caused by ictal epileptiform activity [1]. PNES are diagnosed in at least $10-40 \%$ of the patients seen for long-term monitoring of epilepsy, and are as disabling as epilepsy [2]. Patients with long standing PNES, approximately $10-15 \%$ turn out to have additional epilepsy [3]. The manifestations of PNES often resemble those of ES, and accurate distinction among these conditions is crucial because treatment choice depends on it.

The gold standard test would be the synchronous recording of all events of consideration by video, heart rhythm by electrocardiogram, and electroencephalogram (EEG), and exclude other causes [4]. Thus, it implies

\footnotetext{
* Correspondence: yiguo@zju.edu.cn

Department of Neurology, The Second Affiliated Hospital, Zhejiang

University School of Medicine, No. 88 Jiefang Road, Hangzhou 310009,

Zhejiang Province, China

Full list of author information is available at the end of the article
}

accessibility to a monitoring unit with specialized reviewers and services. Nonetheless, video-EEG (vEEG) monitoring not infrequently fails to capture the events, and it may not differentiate certain types of frontal lobe epileptic seizures from PNES. Besides, vEEG is not without error, and may not be entirely independent of semiology, as its interpretation may partially rely on information gathered from seizure videos. Other limitations include that vEEG is expensive and is not readily available at many centers. Pattern recognition of events forms the cornerstone of interpreting vEEG findings. For these reasons, we decide to focus on semiological characteristics differentiating PNES from ES.

\section{The differences between ES and PNES based on semiology}

PNES pose clinical challenges in terms of diagnosis. Recent studies have thrown further light on the extent to which features of PNES semiology may distinguish PNES patients from those with epilepsy. It's worth noting that single sign is unreliable as diagnostic discriminator, while in clinical practice even informed specialists contextualize multiple signs to hypothesize seizure etiology. Clusters of semiological elements may differentiate PNES more clearly from ES [5]. 
PNES mimic different types of ES, and a classification of PNES would be useful to increase diagnostic accuracy. However, an internationally accepted classification of PNES is not yet available. Several studies have aimed to identify homogeneous groups of PNES based on specific combinations of clinical symptoms and signs, but there is no uniformity of nomenclature.

Magaudda et al proposed a clinical classification of PNES, which classified seizures into four classes: (1) Hypermotor, (2) Akinetic, (3) Focal Motor, and (4) Subjective Symptoms [6]. Seizures mainly characterized by either tonic, clonic, or dystonic generalized movements were considered as belonging to class Hypermotor in correspondence with convulsive ES. Seizures mainly characterized by unresponsiveness and absence of movements were assigned to class Akinetic, corresponding to atonic or absence ES. Seizures with focal motor movements were assigned to Focal Motor in correspondence with epileptic partial motor seizures. Subjective Symptoms seizures were those mainly characterized by experiential phenomena reported by the patients. Though the inter-rater reliability for current clinical classification of PNES is only moderate [7], we adopt the criteria suggested by Magaudda et al to subdivide common symptoms and signs. They proposed four classes corresponding to the most frequently described ones in clinical practice, and classified PNES by considering the most prominent seizure characteristics. It's the first study in which the validity of a new PNES classification was established and reached in subjective level and an automatic analysis framework, as provided by a machine learning (ML) approach.

\section{The semiological differences between PNES and ES irrespective of types of events}

The mean duration of PNES is longer than ES. There is considerable evidence to suggest that a duration of more than 2 min is highly suggestive of PNES, although this is an arbitrary limit. Duration of longer than $10 \mathrm{~min}$ strongly suggests PNES [8]. However, one study including patients with partial ES found the maximum duration of an ES to be $275 \mathrm{~s}$ [9]. PNES occasionally do not exceed $1 \mathrm{~min}$, seen in $4.5 \%$ of the patients in the study by Meierkord et al [10].

Vocalization in PNES patients occurs during or after seizures, and may be complex, with affective content. In contrast, it occurs at the beginning in ES, is primitive, and has no emotional expression [11].

Ictal crying or yelling occurred in $13-14 \%$ of PNES patients and rarely in ES patients [12, 13]. Within PNES patients, Oto et al observed it in $21 \%$ of males and $43 \%$ of females [14]. In conclusion, ictal crying is rather specific for PNES patients, although its sensitivity seems low. Signs of emotional distress suggest PNES.

PNES occur from wakefulness, while the occurrence of ES from sleep is common. However, PNES patients may also provide a history of events "arising from sleep". Duncan et al included 142 patients with vEEG confirmed PNES in a prospective study, and 59\% of them gave a history of events during sleep [15]. Part of this is because of preictal pseudosleep (PIPS), when patient appears to be asleep, but EEG shows activity of wakefulness. Occurrence from PIPS was seen in 12 to $39 \%$ of PNES patients, which was never observed in ES [16, 17]. Of note, Orbach et al reported PNES events occurred during EEG verified sleep or within several seconds of arousal. PNES, in a small minority of cases, represent a psychiatric condition manifesting in sleep, but not the product of the awake mind [18].

Ictal eye closure has been assessed in several controlled studies, and is significantly more frequent in PNES (34-87\%) than ES (0-26\%) [19-22]. Closed eyes during an attack is considered as a discriminator between PNES and ES.

\section{The semiology mainly discriminating Hypermotor and focal motor PNES from ES}

In studies that compared convulsive PNES with generalized tonic clonic seizures (GTCS), the proportion of events with side-to-side head or body movement, especially with coordinated alternating agonist and antagonist activity, was significantly higher in the PNES groups $[19,20]$. However, when comparing PNES with complex partial ES, side-to-side head movement occurred in $20 \%$ of patients in both groups [9]. Similarly, there's no significant difference between PNES and frontal lobe partial seizures [23].

Pelvic thrusting is a specific characteristic associated with PNES. The presence of pelvic thrusting distinguishes convulsive PNES from GTCS. However, there is no statistically significant difference in the frequency of pelvic thrusting between PNES and frontal lobe partial seizures [19, 24].

Brief pauses in rhythmic movement were documented in $47 \%$ of convulsive PNES patients and none of the GTCS patients [25]. Similarly, a waxing-waning tempo was observed in 69\% of PNES and 3.7\% of partial ES [20]. Thus, a fluctuating course distinguishes PNES from generalized and partial ES. Besides, GTCS motor activity frequency declines gradually over the course of the ictus while amplitude increases. In PNES, the frequency of motor activity remains unchanged throughout while amplitude is variable [25].

Asynchronous jerks were seen in 96\% PNES and 5\% GTCS in a controlled study [19]. Chen et al observed asynchronous movements in $44 \%$ of PNES and $7.4 \%$ of partial ES. The presence of asynchronous limb movements distinguishes convulsive PNES from GTCS and partial ES, with the exception of frontal lobe partial seizures. 
Slater et al reported postictal confusion in $67 \%$ of ES patients and $16 \%$ of PNES patients [12]. Similarly, in the study by Azar et al, postictal confusion was seen in $100 \%$ of GTCS and $61 \%$ of frontal lobe partial seizures, but only in $13 \%$ of convulsive PNES [19]. Thus, the presence of postictal confusion distinguishes ES from PNES.

Postictal stertorous breathing has been observed in 61-91\% of GTCS, while in none of PNES [19, 26]. There's no statistically significant difference between PNES and frontal lobe partial seizures, as well as between PNES and complex partial seizures [19, 20].

\section{The nonmotor and subjective symptoms}

Akinetic or unresponsiveness during episodes account for $15-25.4 \%$ of patients with confirmed PNES [27-29]. Mari et al reviewed 110 PNES episodes, consisting of 85 PNES patients and 25 PNES patients who also had epilepsy, but found no significant differences between the two groups in clinical semiology, including unresponsiveness [29].

Cognitive complaints are common in patients with PNES, with memory problems being most frequently reported. Bell et al tested memory during the ictal phase of 245 events, and found that memory items were recalled during $63 \%$ of PNES but only $4 \%$ of complex partial seizures [30]. The sensitivity of memory recall is $63 \%$ for PNES with $96 \%$ specificity.

Different from above, there is insufficient evidence to suggest that gradual onset, flailing or thrashing movements, opisthotonos, tongue biting, trauma, or urinary incontinence as a sign distinguishing PNES from ES. Besides, PNES are generally considered to present with multiple seizure types within and between patients. According to a recent retrospective semiological study, however, neither the stereotypy nor the variability of
PNES can or should be used as a marker of the disease and to differentiate it from ES [31] (see Table 1).

\section{Other points of differential diagnosis}

Semiology provides important diagnostic information, though it's unlikely that a single sign will prove sensitive and specific enough to distinguish PNES from ES. Prospective evaluation of combinations of these signs could lead to the development of validated clinical models.

One limitation is the lack of a standard classification of semiological groups among PNES. As suggested by Magaudda et al, a classification considering too many clinical signs (especially if they were not specific to one class) could cause confusion. To date, most studies concentrated mainly on motor signs, while information of PNES presenting with subjective symptoms or unresponsiveness is scarce. Classes primarily based on motor signs, however, presented the worst rate of interrater agreement. For example, Seneviratne et al classified PNES into six categories: (1) rhythmic motor PNES; (2) hypermotor PNES; (3) complex motor PNES; (4) dialeptic PNES; (5) nonepileptic auras characterized by subjective sensations; (6) mixed PNES [32]. The disagreement concerned more frequently "rhythmic", "complex", and "hypermotor" PNES. Contrary to ES, development of PNES does not correlate with an anatomic organization, often fluctuating, and is difficult to characterize. Furthermore, in cases of prolonged PNES, motor signs can evolve from one class to another.

Establishing the PNES diagnosis requires a clear understanding of the target events through not only the patient's report, but also what other family members, friends or caregivers have observed. One challenge is that seizure witness provide unreliable accounts for seizure semiology. It is proven that discriminating one type

Table 1 Signs and symptoms distinguishing psychogenic nonepileptic seizures (PNES) and epileptic seizures (ES)

\begin{tabular}{|c|c|c|}
\hline & Signs and symptoms favoring PNES & Signs and symptoms favoring ES \\
\hline \multirow{5}{*}{$\begin{array}{l}\text { Differences between PNES and ES irrespective } \\
\text { of types of events }\end{array}$} & Duration of longer than $10 \mathrm{~min}$ & \\
\hline & $\begin{array}{l}\text { Vocalization during or after seizures, complex, with } \\
\text { affective content }\end{array}$ & $\begin{array}{l}\text { Vocalization at the beginning, primitive, } \\
\text { has no emotional expression }\end{array}$ \\
\hline & Ictal crying & \\
\hline & Occurrence from preictal pseudosleep & Occurrence from sleep \\
\hline & Ictal eye closure & \\
\hline \multirow[t]{4}{*}{$\begin{array}{l}\text { Signs and symptoms discriminating } \\
\text { Hypermotor and Focal Motor PNES from ES }\end{array}$} & $\begin{array}{l}\text { Side-to-side head or body movement (compared with } \\
\text { generalised tonic clonic seizures only) }\end{array}$ & Postictal confusion \\
\hline & Pelvic thrusting (frontal lobe partial seizures excluded) & $\begin{array}{l}\text { Postictal stertorous (generalised tonic } \\
\text { clonic seizures only) }\end{array}$ \\
\hline & Fluctuating course & \\
\hline & $\begin{array}{l}\text { Asynchronous jerks (frontal lobe partial seizures } \\
\text { excluded) }\end{array}$ & \\
\hline $\begin{array}{l}\text { Signs and symptoms discriminating Akinetic } \\
\text { and Subjective Symptoms }\end{array}$ & Memory recall & \\
\hline
\end{tabular}


of seizure from another is a learnt skill and requires neurologic training [33]. Acquisition of home video recordings of seizures may lessen the need to rely on eyewitness reports, and should be encouraged.

The situation becomes more complex due to the fact that epilepsy is a recognized risk factor for the development of PNES. PNES occur in 5-20\% of adult populations with epilepsy and $15-40 \%$ of adult referral to epilepsy centers. Differential diagnosis can be challenging without vEEG. That's partly because ES antedate, occur simultaneously with PNES, or even PNES appear as the initial presentation [34]. In practice, the diagnosis is often iterative, rather than a "one shot" process, and long-term clinical follow up may be important.

\section{Conclusions}

Some symptomatic differences help to distinguish ES from PNES, but need to be analyzed by combination of these symptoms and signs, long-term follow-up is sometimes required.

\section{Abbreviations}

EEG: Electroencephalogram; ES: Epileptic seizures; GTCS: Generalized tonic clonic seizures; PIPS: Preictal pseudosleep; PNES: Psychogenic nonepileptic seizures; vEEG: Video-EEG

\section{Acknowledgements}

Not applicable.

\section{Authors' contributions}

Dr. Xiaohui reviewed the literature and wrote the manuscript. Dr. Jiajia was also a major contributor in writing the manuscript. Dr. Yi Guo provided the ideas and modified the manuscript. All authors read and approved the final manuscript.

\section{Authors' information}

Dr. Yi Guo is the member of Comorbidity Committee of China Association Against Epilepsy (CC-CAAE).

\section{Funding}

This work was supported by Department of Education Zhejiang Province Scientific Research Project (No. Y201839721).

\section{Availability of data and materials}

Not applicable

\section{Ethics approval and consent to participate}

Not applicable

\section{Consent for publication}

Not applicable

\section{Competing interests}

The authors declare that they have no competing interests.

\section{Author details}

'Department of Neurology, The Fourth Affiliated Hospital, Zhejiang University School of Medicine, No. N1 Shangcheng Road, Yiwu 322000, Zhejiang Province, China. ${ }^{2}$ Department of Neurology, The Second Affiliated Hospital, Zhejiang University School of Medicine, No. 88 Jiefang Road, Hangzhou 310009, Zhejiang Province, China.
Received: 29 May 2019 Accepted: 11 September 2019

Published online: 21 October 2019

\section{References}

1. LaFrance WC Jr, Devinsky O. The treatment of nonepileptic seizures: historical perspectives and future directions. Epilepsia. 2004;45(Suppl 2):15-21.

2. LaFrance WC Jr, Baird GL, Barry JJ, Blum AS, Frank Webb A, Keitner GI, Machan JT, Miller I, Szaflarski JP. Multicenter pilot treatment trial for psychogenic nonepileptic seizures: a randomized clinical trial. JAMA Psychiatry. 2014;71:997-1005.

3. Benbadis SR, Agrawal V, Tatum WO. How many patients with psychogenic nonepileptic seizures also have epilepsy? Neurology. 2001;57:915-7.

4. Syed TU, LaFrance WC Jr, Kahriman ES, Hasan SN, Rajasekaran V, Gulati D, Borad S, Shahid A, Fernandez-Baca G, Garcia N, et al. Can semiology predict psychogenic nonepileptic seizures? A prospective study. Ann Neurol. 2011; 69:997-1004.

5. Hubsch C, Baumann C, Hingray C, Gospodaru N, Vignal JP, Vespignani H, Maillard L. Clinical classification of psychogenic non-epileptic seizures based on video-EEG analysis and automatic clustering. J Neurol Neurosurg Psychiatry. 2011;82:955-60.

6. Magaudda A, Lagana A, Calamuneri A, Brizzi T, Scalera C, Beghi M, Cornaggia CM, Di Rosa G. Validation of a novel classification model of psychogenic nonepileptic seizures by video-EEG analysis and a machine learning approach. Epilepsy Behav. 2016;60:197-201.

7. Duwicquet C, de Toffol B, Corcia P, Bonnin M, El-Hage W, Biberon J. Are the clinical classifications for psychogenic nonepileptic seizures reliable? Epilepsy Behav. 2017;77:53-7.

8. Dworetzky BA, Mortati KA, Rossetti AO, Vaccaro B, Nelson A, Bromfield EB. Clinical characteristics of psychogenic nonepileptic seizure status in the long-term monitoring unit. Epilepsy Behav. 2006;9:335-8.

9. Pierelli F, Chatrian GE, Erdly WW, Swanson PD. Long-term EEG-video-audio monitoring: detection of partial epileptic seizures and psychogenic episodes by 24-hour EEG record review. Epilepsia. 1989;30:513-23.

10. Meierkord H, Will B, Fish D, Shorvon S. The clinical features and prognosis of pseudoseizures diagnosed using video-EEG telemetry. Neurology. 1991;41: $1643-6$

11. Gates JR, Ramani V, Whalen S, Loewenson R. Ictal characteristics of pseudoseizures. Arch Neurol. 1985;42:1183-7.

12. Slater JD, Brown MC, Jacobs W, Ramsay RE. Induction of pseudoseizures with intravenous saline placebo. Epilepsia. 1995;36:580-5.

13. Walczak TS, Bogolioubov A. Weeping during psychogenic nonepileptic seizures. Epilepsia. 1996;37:208-10.

14. Oto M, Conway P, McGonigal A, Russell AJ, Duncan R. Gender differences in psychogenic non-epileptic seizures. Seizure. 2005;14:33-9.

15. Duncan R, Oto M, Russell AJ, Conway P. Pseudosleep events in patients with psychogenic non-epileptic seizures: prevalence and associations. J Neurol Neurosurg Psychiatry. 2004;75(7):1009-12.

16. Hovorka J, Nezadal T, Herman E, Nemcova I, Bajacek M. Psychogenic nonepileptic seizures, prospective clinical experience: diagnosis, clinical features, risk factors, psychiatric comorbidity, treatment outcome. Epileptic Disord. 2007;9(Suppl 1):S5-58.

17. Thacker K, Devinsky O, Perrine K, Alper K, Luciano D. Nonepileptic seizures during apparent sleep. Ann Neurol. 1993;33:414-8.

18. Orbach D, Ritaccio A, Devinsky O. Psychogenic, nonepileptic seizures associated with video-EEG-verified sleep. Epilepsia. 2003;44:64-8.

19. Azar NJ, Tayah TF, Wang L, Song Y, Abou-Khalil BW. Postictal breathing pattern distinguishes epileptic from nonepileptic convulsive seizures. Epilepsia. 2008:49:132-7.

20. Chen DK, Graber KD, Anderson CT, Fisher RS. Sensitivity and specificity of video alone versus electroencephalography alone for the diagnosis of partial seizures. Epilepsy Behav. 2008;13:115-8.

21. DeToledo JC, Ramsay RE. Patterns of involvement of facial muscles during epileptic and nonepileptic events: review of 654 events. Neurology. 1996;47: 621-5.

22. Syed TU, Arozullah AM, Suciu GP, Toub J, Kim H, Dougherty ML, Wehner T, Stojic A, Syed I, Alexopoulos AV. Do observer and self-reports of ictal eye closure predict psychogenic nonepileptic seizures? Epilepsia. 2008;49:898-904.

23. Saygi S, Katz A, Marks DA, Spencer SS. Frontal lobe partial seizures and psychogenic seizures: comparison of clinical and ictal characteristics. Neurology. 1992;42:1274-7. 
24. Geyer JD, Payne TA, Drury I. The value of pelvic thrusting in the diagnosis of seizures and pseudoseizures. Neurology. 2000;54:227-9.

25. Vinton A, Carino J, Vogrin S, Macgregor L, Kilpatrick C, Matkovic Z, O'Brien

TJ. "Convulsive" nonepileptic seizures have a characteristic pattern of rhythmic artifact distinguishing them from convulsive epileptic seizures. Epilepsia. 2004:45:1344-50.

26. Sen A, Scott C, Sisodiya SM. Stertorous breathing is a reliably identified sign that helps in the differentiation of epileptic from psychogenic non-epileptic convulsions: an audit. Epilepsy Res. 2007;77:62-4.

27. Patidar Y, Gupta M, Khwaja GA, Chowdhury D, Batra A, Dasgupta A. Clinical profile of psychogenic non-epileptic seizures in adults: a study of 63 cases. Ann Indian Acad Neurol. 2013;16:157-62.

28. Perrin MW, Sahoo SK, Goodkin HP. Latency to first psychogenic nonepileptic seizure upon admission to inpatient EEG monitoring: evidence for semiological differences. Epilepsy Behav. 2010;19:32-5.

29. Mari F, Di Bonaventura C, Vanacore N, Fattouch J, Vaudano AE, Egeo G, Berardelli A, Manfredi M, Prencipe M, Giallonardo AT. Video-EEG study of psychogenic nonepileptic seizures: differential characteristics in patients with and without epilepsy. Epilepsia. 2006;47(Suppl 5):64-7.

30. Bell WL, Park YD, Thompson EA, Radtke RA. Ictal cognitive assessment of partial seizures and pseudoseizures. Arch Neurol. 1998;55:1456-9.

31. Asadi-Pooya AA, Tinker J, Fletman EW. How variable are psychogenic nonepileptic seizures? A retrospective semiological study. J Neurol Sci. 2017; 377:85-7.

32. Seneviratne U, Rajendran D, Brusco M, Phan TG. How good are we at diagnosing seizures based on semiology? Epilepsia. 2012;53:e63-6.

33. Seneviratne U, Ding C, Bower S, Craig S, Leech M, Phan TG. Video-based training improves the accuracy of seizure diagnosis. J Neurol Neurosurg Psychiatry. 2014;85:466-70.

34. Wissel BD, Dwivedi AK, Gaston TE, Rodriguez-Porcel FJ, Aljaafari D, Hopp JL, Krumholz A, van der Salm SMA, Andrade DM, Borlot F, et al. Which patients with epilepsy are at risk for psychogenic nonepileptic seizures (PNES)? A multicenter case-control study. Epilepsy Behav. 2016:61:180-4.

Ready to submit your research? Choose BMC and benefit from:

- fast, convenient online submission

- thorough peer review by experienced researchers in your field

- rapid publication on acceptance

- support for research data, including large and complex data types

- gold Open Access which fosters wider collaboration and increased citations

- maximum visibility for your research: over $100 \mathrm{M}$ website views per year

At $\mathrm{BMC}$, research is always in progress.

Learn more biomedcentral.com/submissions 